\title{
NATURALISM'S MAXIMS AND ITS METHODS. Is NATURAlistic Philosophy LIKE SCIENCE?
}

\author{
CARIN ROBINSON \\ The University of KwaZulu-Natal, SouTH AFRICA \\ carin.b.robinson@gmail.com
}

\begin{abstract}
This paper argues that naturalistic philosophy does not meet its own empiricist mandate. It argues from an empiricist perspective. Naturalists either claim that philosophy is like science in significant ways, or they claim that philosophy ought to be like science. This paper, being chiefly focused on the former claim, argues that naturalistic philosophy is nothing like science. Using Papineau's markers for the similarities between naturalistic philosophy and science, I argue, counter Papineau, that the method employed in naturalistic philosophy is not a posteriori and its claims are certainly not synthetic in the same way as that of science. This methodological distinction between science and philosophy is one made by Carnap. To show how the methods are distinct I compare two papers; I compare the method employed by Andy Clark in his philosophical paper on the brain as a prediction error minimisation machine with that employed by Rees and Haynes in their neuroscientific paper on mental content.
\end{abstract}

Keywords: Naturalism $\bullet$ science $\bullet$ methodology $\bullet$ synthetic $\bullet$ a priori $\bullet$ a posteriori.

\section{Introduction}

A fundamental tenet of analytic philosophy, from its post-Tractatus phase onwards, was that there is a sharp distinction between philosophy and science. Philosophy ... whether or not it is conceived to be a cognitive discipline, is conceived to be a priori and hence discontinuous with, and methodologically distinct from, science. Similarly, analytic philosophy in general held that questions of meaning antecede questions of truth, and are separable from empirical questions of fact. If Quine is right, then analytic philosophy was fundamentally mistaken. (Hacker, 1996)

The ongoing and resolute self-auditing project with which philosophy engages has one branch which is the relationship philosophy has with science. It is evidently of concern to philosophers what they can, given their tools, legitimately claim about the nature of reality. One subsidiary branch is the very current and live debate about naturalism. In some of the most recent literature investigating philosophical methodology (Haug 2014) naturalism is accused of being ill-defined, unfaithful to Quine, too 
faithful to Quine, stronger and weaker versions of naturalism are proposed, some versions of it are argued to be redundant and pleas are made for new versions. In response, defences of 'armchair' philosophy include investigations into whether logic can describe the world, full blown defences of a priori metaphysics and defences of epistemology as an inherently a priori discipline.

But I find the strongest advancement of naturalism, given its mandate, to be that naturalistic philosophy is like science (Papineau 2014), or ought to be like science (Maddy 2007). And the corollary of that is that I find the most damning accusation of naturalism to be that it is not, nor can it be.

Philosophy is never done in a way which characterises it as an a posteriori discipline. And even when it boldly trades in scientific truths, its method is still not the same as that of scientific investigations. Naturalistic philosophy is, like all philosophy, executed in an armchair, and no amount of deference to science, and engagement with science, is enough to lift it out.

I argue as follows:

Premise 1: Scientific claims are justified a posteriori

Premise 2: Scientific claims are synthetically true, if true

Premise 3: Most naturalistic philosophical claims are not justified a posteriori

Premise 4: Most naturalistic philosophical claims are not synthetically true, if true Conclusion: Therefore, most naturalistic philosophical claims are not like scientific claims

We shall take 'scientific claims' to refer to the sorts of claims which are the final product of scientific research. In other words, the results of scientific research. Similarly, philosophical claims are the final claims, the conclusions, of philosophical work or argumentation. For present purposes Premises 1 and 2 I shall take as uncontroversial, and true. They are, at least, uncontroversial in the sense that naturalists themselves acquiesce to this. ${ }^{1}$

Persuading my reader of the truth of premises 3 and 4 is the task at hand. This persuasive work has two phases: 1. By Papineau's permissive construal of 'synthetic' and 'a posteriori' nearly all philosophy gets to be like science. Even philosophy which naturalists themselves should reject, or is obviously not like science. This does not bode well for the delineating criteria set by Papineau. It seems, for naturalism to be like science the bar for what qualifies to be science-like is lowered to such a degree that much else qualifies too. ${ }^{2}$ Naturalism, in this sense, becomes nearly self-defeating. 2. But even once we have a better explication of 'synthetic' and 'a posteriori' - such as what naturalistic philosophy would need to be actually like science - it turns out that naturalistic philosophy fails to qualify anyway. The second part I hope to do by 
showing how Clark's paper, 'Whatever Next?', which is exemplary naturalistic philosophy, is nothing other than an attempt to draw connections between facts which come from a myriad different sources over extended periods of time, combined with some seminal philosophical instincts to give his reader an elegantly argued grand unified theory for all brains. This is to be compared to the closely knit empirical justification offered for the extraordinarily conservative claims Haynes and Rees make in 'Decoding mental states from brain activity in humans'. My point: If Haynes and Rees' method is a posteriori, then Clark's cannot also be - they are simply too different.

Please note, I use 'exemplary' here in the proper sense of the word; as meaning a typical example of naturalistic philosophy. Clark's work is exemplary (i.e. typical) naturalistic philosophy as it features all the traits Papineau proposes as typical of naturalistic philosophy. These are not traits which I propose. So, to suggest, in response to this paper, that Clark might simply be the wrong ambassador for naturalistic philosophy is to, in effect, take exception to the description of naturalistic philosophy offered by Papineau.

In section 2 I offer an explication of 'naturalism', and explain its own standards for scientistic philosophy. For this I look at the most salient features of naturalistic philosophy as forwarded by both Papineau (2014) ${ }^{3}$ and Maddy (2007). Over sections 3.1 and 3.2 I compare two research papers on mental content; one by a philosopher, Andy Clark (2013) and another by neuroscientists, Haynes and Rees (2006). In section 4 I explain why there is a failure at kinship between the examples used.

\section{Some seminal explications}

Naturalism holds that '... philosophical investigations are not superior to, or prior to, investigations in the natural sciences, but in partnership with those truth seeking enterprises ...' (Dennett 2003, p.15). The philosophical auditing of naturalism asks whether or not philosophers should defer to science, whether scientism in philosophy means the end if its a priori traditions or whether it is even plausible that philosophers can effectively engage with science. The naturalism debate is sometimes framed in a traditional philosophical lexicon, using the contested distinctions between a priori and a posteriori knowledge and analytic and synthetic truth. Despite the fact that some naturalists deny the meaningfulness of terms such as 'analytic' (Quine 1963; 1963a) or deny their applicability since they are not scientifically credible (Maddy 2000; 2007), there are others (Papineau 2014) who have used these terms to demonstrate how philosophy - within reason — is, in fact, already like science. There has not been enough said in very recent literature about the last claim.

'Naturalism':

There is only the natural world, and the best way to find out about it is by the scientific method. (Williamson 2014a, p.29). 
In this sense I too am a naturalist. However, the controversial part that Williamson forgets to add is the part that Papineau adds; philosophy, especially naturalistic philosophy, is like science. But the suggestion, by naturalists, that they themselves can be scientific in their philosophical endeavours is a demand which is certainly not being met (Hacker 2005, Wolff 2015).

For a school of thought, such as logical positivism or Quinean naturalism, to be scientistic is for it to have a special and high regard for science. What this regard is based on may vary, but we broadly refer to such a regard for science as 'scientism' (Haack 2009). The self-auditing of scientism in philosophy has ranged from it being thought of, pejoratively, as a myopic and misguided reverence of science, to an acceptance of scientism as an appropriate philosophical attitude for particular types of knowledge seeking enterprises, to an 'honorific' attitude towards science, by philosophers (Haack 2009, pp.1-4). If scientism in philosophy holds that 'The simple idea is that no extra-scientific method of justification could be more convincing than the methods of science, the best means we have...' (Maddy 2009, p.438) then naturalism invokes a type of scientism.

But the objective set out for this paper will not be met unless naturalism is measured against a particular construal of 'science'. What 'science' refers to is, of course, very broad. Nevertheless, 'science' is used liberally, and often without strict qualification, by naturalists themselves and also by their opponents (see Williamson quote above, for instance). But, let us settle here on a sort of working explication for 'science' which is one that naturalists are committed to for their mandate to take hold.

If science is taken to be characterised chiefly by the deductive hypothesising and mathematically abstract work that we find, for instance, in theoretical physics then the comparison with the reasoning activities of naturalistic philosophers might, prima facie, be easier to make. However, naturalism is simply not entitled to draw an analogous relationship with the theoretical sciences. Why not? Why can the naturalist not simply hold that good naturalistic philosophy, like theoretical science, provides a coherent system of theories and claims, where the empirical foundations for such systems are also known to the author?

For two reasons, which I shall only briefly list here: 1 . Where philosophy is theoretical it is not theoretical in the same way as science is. The theoretical and deductive parts of, for instance, physics are actively linked to ongoing empirical testing and observation. They are linked to working hypotheses. They are tested against the hypotheses which stand in opposition to them. They are the products, and points of discussion, of a collegial and academic environment of specialised scientific experts. To the contrary, deductive systems in philosophy, even when premised on empirical, scientifically derived claims, are sequestered from the areas of research from which they draw. And where there might be points of contact with the contributions that philosophers make, philosophers' contributions are of a particular nature. This 
is what I hope to show going forward. The point for now is: Theory and deduction in philosophy and theory and deduction in empirical science do different types of work. Philosophy and science are not akin simply because they both sport theoretical and deductive aspects to them. 2. There is a strong case to be made that the theoretical parts of science are conventional and analytic. This is, of course, something the naturalist will deny since most naturalists deny the possibility of analytic truth altogether. Unfortunately, this is not a line of argument this paper can pursue. Fortunately, however, we do not need it to make the points which are made below.

For the naturalist to distinguish the right sort of philosophy from the wrong sort (Maddy 2000; 2007; 2009) and to hold that it trades in synthetic a posteriori truths (Papineau 2014), naturalism has to be married firmly to the experimental and observational aspects of science - even if these are not the only actual aspects of scientific work. This is its only chance to give credibility to its claims of being analogous to science. We have been told in no uncertain terms that naturalism sets itself apart from the rationalism of Descartes and Spinoza and even the empiricism of Carnap which all appeal to deductive systems and abstract reasoning while many parts are expected, by those philosophers, to make contact with empirical reality. So it must be the observational and experimental, ${ }^{4}$ feature of empirical science which informs the naturalist project.

About 'science': It follows then that for naturalists the philosophically salient feature of science ought to be that which has naturalists claiming that philosophical claims, like scientific claims must be '... justified a posteriori...' (Papineau 2014, pp.184-6) and '...there is a distinction to be drawn, within science, between hypotheses that are subjected to the full range of empirical testing and available for full confirmation, and those that are not...' (Maddy 2000, p.110).

So, is the method of naturalistic philosophy like the method of scientific investigations? I shall argue that the answer to this question is an unequivocal 'no'. Their methods are distinct and therefore also their products. And it is this exact sequence, i.e. that method of justification determines the type of truth of the claim, which is a leading moral for the arguments to follow. I take this moral from Frege.

'Synthetic' and 'a posteriori':

Now these distinctions between a priori and a posteriori, synthetic and analytic, concern as I see it, not the content of the judgement but the justification for making the judgement. Where there is no such a justification, the possibility of drawing the distinctions vanishes. (Frege 1974, p.3)

In contrast to Frege, we shall see in the next section that not only does Papineau take 'synthetic' to refer to the content of a statement, but he seems to take the content to be determined simply by an attitude towards a knowledge seeking enterprise that of making factual claims. 
This critique of naturalism is not concerned to show that naturalistic philosophy is philosophically moribund because it cannot answer traditional philosophical questions. Nor is it concerned to defend the place of the a priori in knowledge seeking enterprises. It is also not a defence of conceptual analysis. All the aforementioned strategies against naturalism are familiar and regularly form respectable components of a campaign against naturalism. Some of them are worthy strategies, but are not the present concerns. There is also much that can be rightly said about the 'unclarity of naturalism' (Williamson 2014b) — but it is not the purpose of these arguments to do this. One such 'unclarity' is, however, alluded to in this paper: That one naturalist holds that philosophy — within reason — is already like science (Papineau) and another holds that it should change its practice in order to be like science (Maddy). Other pitfalls which give rise to this lack of clarity are, for instance, 1 . that there is no agreed on view of the scientific method (Williamson 2014b, p.37) and 2. that defences of philosophical positions, such as naturalism, are in themselves unscientific or dogmatic (Williamson 2014b, p.38; Van Fraassen 2002).

\section{Naturalism's standards for being akin to science}

It will come as no surprise that the promulgation of naturalism comes in both prescriptive and descriptive forms. Maddy (2007) is chiefly engaged in a revisionist campaign for philosophy; how philosophy ought to be done. On the other hand, Papineau's (2014) descriptive account holds that philosophy already meets the most important criteria for being like science. ${ }^{5}$

Papineau claims that science and philosophy are alike because: 1 . Philosophical claims are synthetic. 2. Philosophical knowledge is a posteriori. 3. Philosophy is motivated by the same research questions as science (Papineau 2014, pp.166-7). Furthermore, like scientists, philosophers are not concerned with the supernatural (Papineau 2014, p.167). Philosophical work, even when utilising its quotidian tools, is already like science in the abovementioned ways.

I do not intend these claims in a revisionary spirit. I am not recommending that philosophers start doing something different. Here I diverge from other philosophers in the methodological naturalist camp who take their position to require a shift in philosophical method - philosophers should get out their armchairs and become more involved with active scientific research. This is not my view. When I say that philosophical investigation is akin to scientific investigation, I am not urging philosophers to change their ways [...] My aim is to show that philosophy of this kind is already akin to science, not that it needs reforming in order to become so. (Papineau 2014, p.167)

For Papineau, what makes a statement or concept synthetic is not, as it is for 
Frege, that the method of justification decides the alethic character of philosophical concepts. Philosophy trades in synthetic truth because philosophers incur 'synthetic commitments' (Papineau 2014, pp.170-1). This is the case even when they are concerned with the elucidation of 'theoretical tangles'. Likewise, their commitment to making factual or substantial claims is evidenced by their use of inferential concepts, because inferential concepts are inevitably linked to theories which always have synthetic application and significance (Papineau 2014, pp.168-9). He speaks about these concepts as 'manifestly synthetic' (Papineau 2014, p.169). Contrary to what some philosophers take themselves to be doing 'we can see that they are in fact concerned with synthetic and not analytic matters' (Papineau 2014, p.168). It seems that 'synthetic', for Papineau, is a function of something like a disposition, or a mind-set. It is the 'matter' with which we are concerned and our disposition towards that matter.

Furthermore, there is no need to think of counterfactual reasoning, or using the method of possible cases, as doing purely conceptual work (Papineau 2014, p.176). Counterfactual reasoning '... evince[s] synthetic as opposed to purely conceptual intuitions...' (Papineau 2014, p.176). He argues, by way of examples from within science, that counterfactual reasoning, a favourite tool of philosophers, is a method of knowledge acquisition which is not only analogous with scientific experiments but is also something that scientists themselves do (Papineau 2014, pp.176-7).

Nevertheless, he admits, philosophers do not do experimental or field work. They think. They argue. They imagine. They intuit. They use thought experiments. They reason counterfactually. And the scientific character and worth of philosophical claims generated in these manners is tied up with the fact that these claims form part of the thinking which leads to empirical field work and confirmation or disconfirmation of theories (Papineau 2014, pp.183, 185, 186). And this confirmation is permitted to be, as in science, indirect (Papineau 2014, p.181).

Unlike Papineau, Maddy holds that philosophy is on the whole not scientific enough. But, she thinks it ought to be. She forwards a loosely articulated set of principles for philosophical enquiry. The idea is that if these are met, philosophy would have made a decent enough appeal to science so as not to be guilty of the traditional, a priori or first philosophical investigation that so taints its character. Maddy, in Second Philosophy (2007), urges philosophers to concern themselves with the 'scientific versions of traditionally philosophical problems' (Maddy 2007, p.117). She holds that the only philosophical questions which are worthy of attention are those that science can resolve, and that a second-philosopher should be in good standing to do so. Her conception of second philosophy is that it is roughly scientific (Maddy 2007, p.15). But Maddy is keen to keep her explicit commitment to what 'scientific' means to a minimum. 
My point is that our inquirer needn't employ any general analysis of what counts as 'scientific' to say this sort of thing, though we use the term 'science' in its rough and ready sense when we set out to describe her behaviour (Maddy 2007, p.15).

Perhaps this is more helpful: What is not scientific to Maddy is meta-level thought of the type which resembles Kant's transcendental idealism and Carnap's meta-linguistic analysis - which she takes to have significant similarities (Maddy 2000). Further examples are the arguments in semantics of philosophers like Crispin Wright (Maddy 2007, p.117). She, for instance, describes how a second philosopher would undertake the problem of skepticism about the existence of our hands, as raised by Descartes (Maddy 2007, p.16). Maddy says that the second philosopher would recast this debate in terms which are more familiar to scientists than to philosophers. Like a scientist, the second philosopher does not address this problem by undertaking a meta-level discussion, employing traditional epistemological terms such as 'a priori', 'a posteriori' or 'analytic' and 'synthetic' (Maddy 2007, pp.47-64). These are terms which are not useful to the second philosopher because there is no way to make scientific sense of them. So about whether we have hands or not

...our inquirer will tell a story about the workings of perception - about the structure of ordinary physical objects like hands, about the nature of light and reflection, about the reactions of retinas and neurons, the actions of human cognitive mechanisms, and so on. (Maddy 2007, p.16)

The philosopher is, therefore, asked to know things about the human and/or other animals' nervous system, the biological basis of mental states, perception, the physics of colour and so on. Like scientists, philosophers should not be encumbered by quaint and arcane philosophical problems such as skepticism, meta-theoretical categories of knowledge and truth, metaphysical problems about causation and epistemological problems about reference. Philosophers should ask and answer questions that science can. Philosophers are expected to participate in the scientific fields relevant to their inquiries.

Experimental philosophy is one type of philosophical endeavour which fulfils the mandate for good naturalistic philosophy. It aims to answer philosophical questions with appeal to experimental work done. Similarly, cognitive science.

Second, it [cognitive science] is interdisciplinary: ideas and methods of inquiry propagate across traditional boundaries, and collaborations thrive among founding fields and also philosophy, sociology, anthropology, developmental psychology, education and neuroscience. (Abrahamsen and Bechtel 2012, p.9)

About the role of philosophers in investigating cognition in a more empirical manner, Abrahamsen and Bechtel say that, for instance, philosophy of mind has '....inspired 
certain lines of empirical research' and '... its concepts, theories and tools gets adapted or applied by researchers in other cognitive disciplines' (Abrahamsen, A. and Bechtel, W. 2012, p.10). A paper in cognitive science has likely drawn from a range of theories and models, yielded from a range of disciplines, some of these from within the natural sciences. A research paper in cognitive science has, therefore, also relied, directly and indirectly, on a range of methods for investigation. Arguments from cognitive science are often exemplary naturalistic arguments; those which present premises from within the physical and natural sciences and incorporate these into arguments.

Philosophic naturalism simpliciter is the view that scientific conclusions are appropriate elements within philosophical arguments; thus naturalism contrasts markedly with the views of philosophers such as Wittgenstein of the Tractatus [...] who claim that philosophical argumentation must always be conducted prior to any attention to scientific theories. (Popp 2007, p.11)

\section{Defending Premise 3: Why most naturalistic philosophical claims are not a posteriori}

Section 3 consists of a comparison. The aim of providing this comparison is simply this: To show the difference in methods of justification between a typical naturalistic philosophical paper and that of a typical scientific paper. Taking a posteriori to refer to a type of justification (and, therefore, a type knowledge) we know that naturalists hold that scientific claims are justified a posteriori. And we have noted that naturalists take the claims generated by naturalistic philosophy to be like those of science; $a$ posteriori. In section 3.1 we look at a philosophical paper of the naturalistic type (one which meets both Papineau and Maddy's conception of naturalistic philosophy), and in section 3.2 we look at a scientific paper. And we shall see that their methods are entirely different. The suggestion is, this difference is not peculiar to just these two papers.

This means that we have either something like a serious equivocation when using the term a posteriori as Papineau does in The Poverty of Conceptual Analysis or there are different measures or standards applied for science and philosophy. Either way, there is certainly an unacceptable vagueness; one which wrongly permits the much coveted kinship. My point is that if a posteriori is what we call scientific claims because of the method with which they have been justified then the same term cannot describe philosophical claims, even of a naturalistic type. 


\subsection{Whatever Next?; a philosophical paper on mind}

Clark's (2013), 'Whatever next? Predictive brains, situated agents and the future of cognitive science', presents exemplary naturalistic philosophy. It draws from various forms of natural science to build its arguments and are consistent with our best evolutionary theories. Whether unwittingly or not, Clark, in this paper at least, is a naturalistic philosopher. More importantly, he is by Papineau's standards.

Clark provides a study of predictive models $_{2}{ }^{6}$ of the brain, and the nuanced changes they have been through since Helmholtz, 1860, to current models $s_{2}$ (Clark 2013, p.182). This component of Clark's paper is thus a second order analysis of the literature about predictive coding models ${ }_{2}$. The first order component allegedly gives us empirically based reasons why the brain is a prediction 'machine'. It is this aspect of 'Whatever Next?' which concerns me. Let us take this to be Clark's conclusion:

Clark conclusion:

Brains are prediction machines. (Clark 2013, p.181)

In terms of first-order claims, Clark takes his model of cognition to be consistent with evolutionary theory (Clark 2013, pp.193, 194, 195, 197, 200) as well as findings from within neuroscience (Clark 2013, pp.190, 191, 201). Clark gives his reader reasons why a predictive coding model $_{2}$ will very likely enjoy universal status; it is likely to be the one correct and grand unifying theory about the brains of all animals (Clark 2013, p.200).

This is Clark's justification: The favouring of predictive models ${ }_{2}$ of the brain is supported by the fact that they are powerful theoretical tools. They come closer than any other available models $s_{2}$ of the brain at connecting action, perception and inference in a grand unified theory (Clark 2013, p.201). Yet, despite there not being much empirical evidence supporting a predictive coding model, firstly, merely as an empirically plausible model, and, secondly, even less so as a grand unified theory for all brains, he remains optimistic (Clark 2013, p.201).

Some indirect empirical support and only very little research offering direct support for predictive coding is available:

However, direct neuroscientific testing of the hierarchical predictive coding model, and of its action-oriented extension, remains in its infancy. The best current evidence tends to be indirect... (Clark 2013, p.191)

One limitation of these models - and of predictive coding in general is that to date no single neuron study has systematically pursued the search for sensory prediction error responses (Summerfield and Egner 2009, p.408, Clark 2013, p.192)

... in another way it can still seem disappointing. If what we want to understand is the specific functional architecture of the human mind, the distance 
between these very general principles of prediction-error minimization and the specific solutions to adaptive needs that we humans have embraced remains daunting. (Clark 2013, p.193)

Clark has used argumentative means by which to construct and defend his model $_{2}$ of, and proposed grand unified theory about, the brain and mind. And even though the second order component of his paper ought not to be taken as evidence for his first order claim, it is by him.

He constructs a train of thought which is supposed to, by means of something like abductive inference, persuade us to accept the high probability of his model of cognition being empirically accurate. Much of the persuasive capital comes from the historical robustness of prediction error minimisation theory. Added to the historical success is a sort of cherry picking exercise of choosing scientific claims from a variation of experiments and observations, spanning decades. Most of these experiments have very little, if not nothing, to do with each other - except where Clark infers connections. So, his argument is impressively studded with citations of theories from within various types of science, but less so with citations of directly relevant experiments and observation supporting his primary claim. This makes the interdisciplinary and inter-theoretical coherence good, but very wide-ranging. It leaves the relationship between direct evidence and theory (his theory) very thin. ${ }^{7}$ Papineau would call Clark's method a posteriori and his claim synthetic.

None of what he has done looks similar to a scientific paper on the same topic. We shall see shortly, his work is not a posteriori like the work undertaken to produce a paper in neuroscience. Nor will most other naturalistic philosophy of a similar kind be a posteriori in the way needed to demonstrate methodological kinship. If his method is a posteriori here, then the a posteriori work of scientists should be called something else.

If we find that the two case studies seem to not be similar enough, yet science we take to be a posteriori, then we would have come some way towards showing that:

Premise 3: Most naturalistic philosophical claims are not justified a posteriori

\subsection{Decoding mental states from brain activity in humans; a scientific paper on mind}

Haynes and Rees's 'Decoding mental states from brain activity in humans' (2006) considers the possibility of predicting mental states from measuring brain activity. The implications of being able to do so with some accuracy is, of course, to be able to link the content of our thoughts to certain areas of the brain.

Is it possible to tell what someone is currently thinking based on measurements of their brain activity? At first sight, the answer to this question might 
seem easy. Many human neuroimaging studies have provided strong evidence for a close link between the mind and the brain, so it should, at least in principle, be possible to decode what an individual is thinking from their brain activity. (Haynes and Rees 2006, p.523)

Let us see what a posteriori justification looks like in a neuro-scientific investigation.

Haynes and Rees use non-invasive methods when doing multivariate readings, measuring electrical potential measured on the scalp or otherwise by blood-oxygendependent functional MRI signals (Haynes and Rees 2006, p.524). They discuss two methodologies available to neuroscientists in trying to decode brain states. There is therefore also a second order component to their paper. However, they draw first order conclusions about what their studies might or might not show about the actual relationship between the brain and the mind. They ask whether at all, and if so how, mental content can be known and predicted by measuring brain activity.

To answer this question they compare, what they call, 'conventional' approaches with 'multivariate' approaches to measuring brain activity. The most obvious distinction between these two approaches is that conventional approaches attempt to establish very directly, let us say, one to one, associations of particular parts of the brain with particular mental states (and perhaps even more complex thought) (Haynes and Rees 2006, pp.523-4). The motivation underlying conventional approaches is to show that distinctly isolated brain states are correlated to specific mental content. Once this is done, brain measurement can indicate what is being thought (unconsciously or/and consciously). The point is, a one to one correlation, which conventional approaches aim for, is neat and easily managed in terms of predictive efficacy (Haynes and Rees 2006, pp.523-4).

Multivariate approaches are different from conventional ones in this way: A multivariate approach prescribes measuring brain activity at more than one location at one time. This is followed by doing repeated measurements under identical conditions to observe patterns of activity across one brain, when repeatedly exposed to the same stimulus. Both approaches can use the same data collected. The authors claim that measuring sensitivity to activity over the whole brain, over repeated instances, produces better results for neuroimaging (Haynes and Rees 2006, p.523), and therefore knowing and predicting mental states.

One benefit of doing these types of readings, i.e. multivariate, as opposed to localised readings, is that it is possible to do readings of perceptual and cognitive states while these states are being experienced. For this to happen there has already been a statistical analysis done on a particular brain's activity under carefully identified and isolated conditions. This analysis is then incorporated into a final reading whilst the brain is being exposed, thus giving, what they call, 'quasi-online estimates' (Haynes and Rees 2006, p.524). 
But in nearly equal measure they explain where their research methodology's weaknesses are. They say, the financial costs of the type of research done by them, make it extremely hard to apply their research to 'real-life' situations (Haynes and Rees 2006, p.529), or put another way, repeat in non-artificial situations. This means that, as with any artificially designed experiment, there remains the problem of contingencies and variances in the non-laboratory world, which might partially or completely refute experimental results. Scientific practice is to draw conclusions relative to the experiment and not to infer and extrapolate too far beyond these confines. They maintain that whether accurate predictions of thought can be made by measuring brain patterns when the brain is engaged with the real world (as opposed to in a laboratory), is very far from established conclusively (Haynes and Rees 2006, pp.529, 530).

Their complete investment in their a posteriori methods has two further obstacles: 1 . Problems with generalisation and invariance, both over time and across instances of the same mental state, but read at different sessions (Haynes and Rees 2006, p.529), 2. Problems with extrapolation to novel perceptual or cognitive states (Haynes and Rees 2006, p.531). The first has to do with just generalisations about the simple brain states with which their paper chiefly concerns itself. The latter with the problems of knowing the intricacies of more complex thought, and not just a mental state, based on the crude measurement of simple brain states. It is one thing being able to say 'this person registers an image' and quite another to start predicting our thought in its more complex form, such as the mental content of belief and prediction and propositional attitudes.

About the problem with inference to novel perceptual or cognitive states: Their cautionary note here is that the accurate measurement of brain activity and prediction of mental states, or vice versa, does not permit inference to the exact content of the associated thought (Haynes and Rees 2006, p.531). Haynes and Rees discuss what would be required for prediction of such thought to be made possible. It '... will ultimately depend on the ability to measure the neural structure of the underlying semantic representations' (Haynes and Rees 2006, p.531). They are quite adamant that the decoding method they have devised is very far from being able to measure, predict or explain mental content of this type. Furthermore, the authors caution that such decoding methods are 'based on inverse inference' (Haynes and Rees 2006, p.531). This means that they have started with a set of phenomena and inferred (or suggested, rather) causes of the phenomena. But inverse inference is famously moot, they say. They maintain that what they have not established is that the brain states under investigation are causally connected with the mental content associated with them.

Even if a specific neural response pattern co-occurs with a mental state under a specific laboratory context, the mental state and pattern might not be 
necessarily or causally connected. (Haynes and Rees 2006, p.531)

Compare all of the above to Clark's seminal claim - mooted as an eventual GUT, 'Brains are prediction machines'. The type of a posteriori justification needed to support Clark's claim, if it were akin to the a posteriori justification Haynes and Rees's offers, would be nothing like what Clark offers his reader in Whatever Next?.

Haynes and Rees's primary claim is:

When using multivariate approaches for measuring brain activity, under laboratory conditions, it is possible to sometimes predict basic brain states (mental content). Adapted from (Haynes and Rees 2006)

Their research paper has offered a description of their extensive empirical work, which has been done in direct response to the claims they make: they have tested an hypothesis. They have explicitly cautioned where, and why, they think their methods have not been able to assist with supporting their primary claim. If their work is a posteriori, then their primary claim is synthetic. And I think there are very few who would disagree with their work being a posteriori. What is not the case, is that their claim wins synthetic status because they have a 'synthetic commitments' (qua Papineau) to their research question, or because they do not take themselves to be engaged in analytic theoretical untangling, or because they take themselves to be making claims with empirical content. More importantly, if Haynes and Rees' work is a posteriori then Clark's is definitely not. And if these two papers are typical of their respective disciplines, then

Premise 3: Most naturalistic philosophical claims are not justified a posteriori

\section{Permissive rules}

Perhaps the original shared identity, and the long and intertwined histories of science and philosophy reflect a sort of familial relationship; a kinship. And, yes, there are many shared interests. But the forms which they respectively take make them very little like each other in actual kind. Haynes and Rees' conservative claims, expressly constrained by the limitations of their empirical observation, when compared with the proposed grand unified theory of Clark, generated not within the ambits of scientific investigation proper, but from an armchair and a desk, make the distinction between philosophy and science seem very stark.

Note, the worry here with the way Clark draws his inference, or his best explanation, is not that his claim is indirectly related to the evidence he uses. Scientific claims are often only indirectly related to the evidence supporting them. It is that the 
evidence Clark uses is a motley group of disparate theories, some with good scientific standing, and some with good philosophical standing, but with no empirically demonstrable relationship to even each other; not in type nor in content. Clark's 'inference to best explanation' is, at best, a good summary, an analysis, of a wide ranging set of theories generated over a very long period of time.

Irrespective of how familiar a trained philosopher has become with the literature generated from a specific field of empirical science, there cannot be the sort of comprehension, broad and narrow, of the empirical considerations giving rise to scientific research papers. Wolff (2015) levels a charge against naturalism which questions the epistemological plausibility of the second philosopher. ${ }^{8}$ She holds that Maddy has offered us an idealised enquirer. In doing so, '... Maddy has created a monster', she says (Wolff 2015, p.12). The reason is that, despite the requirement for scientific validation of philosophical questions and corroboration of philosophical answers, most philosophers, even when scientifically literate, do not specialise in the natural or physical sciences in the required manner.

This enviable epistemic position is not one many of us can claim for ourselves. Instead we find ourselves outsiders with respect to most scientific fields, even if we can claim to be an expert in one. Indeed, the overall development of scientific inquiry seems to point in the direction of more narrow specializations, with larger numbers of participants involved in any given project. (Wolff 2015, p.12)

Like mastery in philosophy, mastery in science runs deep. The results of having involved oneself, as a trained scientist, in scientific hypothesising, the technical competence demanded for understanding the intricacies of competing scientific theories and empirical research and how to construct hypotheses so that they can be tested, are not to be inculcated by the philosopher simply by carefully reading and studying scientific research papers. This is the case even if relevant scientific terms seem to be a properly entrenched part of a philosopher's lexicon and the research methodology comfortably familiar.

To sit in one's armchair and compare pivotal claims from papers from within science or papers from where philosophers and scientists have collaborated is not to do science. It is not a posteriori justification. This is conceptual labour; its primary activities are reading, analysis, evaluating and arguing. The primary content might be generated by science, but the method employed for drawing further inferences is not itself scientific. Scientists are trained in the research methods particular to that kind of study and are, presumably, steeped in the content of the relevant subject matter, as well as the surrounding and competing research and theories of their colleagues. And this training is an inch wide and mile deep.

The Second Philosopher's attitude towards inquiry might then simply seem 
like one we cannot possibly adopt, and as such her advice might be unsuitable given the kinds of inquirers we in fact are. (Wolff 2015, p.12)

But perhaps engaging scientific truths in philosophical arguments is to work 'alongside science' (Dennett 2003). Yes, perhaps indeed, if scientists really do use the rational and argumentative work, and resulting conceptual truths, on offer by philosophers. If so, then it might be that philosophers do, in this respect, work alongside scientists. It is by no means the intention here to say that philosophers have no part to play in scientific endeavour. We know that often empirical theories are underpinned by philosophical theories (Friedman 1997, p.17). ${ }^{9}$ The point, throughout, has been to say that unlike what philosophers sometimes think of themselves doing, their work is not the same as the work scientists do. And following from this, their products are distinct too.

Yet Papineau still thinks that what naturalists do is enough to make their work comparable to that of the work of scientists. He makes the comparison by insisting that 'a posteriori' and 'synthetic' apply in the same manner to both philosophy and science. And the only way in which he can make these terms fit both science and naturalistic philosophy is by dropping the bar of what they refer to. It is this permissive construal of 'synthetic' and 'a posteriori' which undermines the self-imposed naturalistic standards for kinship with science. Churchland's (1981) flagrant sciencefiction in 'Eliminative Materialism' get in, some examples of systematic theology gets in, Spinoza's 'Ethics' gets in. Papineau's criteria seem too easily met.

When the bar is this low for what counts as synthetic and a posteriori there is a danger of doing bad philosophy, not to mention no chance of being akin to science. In fact, to claim that theoretical untangling activities yield anything but conceptual clarity is to step into the murky waters of the synthetic a priori - a long standing and well acknowledged enemy of good empiricist philosophy. And even if 'synthetic a priori' is a vacuous term for some naturalists (qua Maddy), it suffices to say that to engage in theory untangling activities, and to think of doing so as being empirical, is to be both philosophically naïve and scientifically barren. No such untangling exercise, given the patently a priori method employed for doing so, should be thought of as proffering synthetic truths. Even if they are very illuminating. Similarly, to attempt to '... unify the often warring perspectives into a single vision of the universe...' (Dennett 2003, p.24) while pouring over books and papers and applying one's, even formidable, mind to this gargantuan task is nothing but good old-fashioned rationalist metaphysics. ${ }^{10}$

Naturalist philosophers do not do their work like scientists do. Nor do the claims generated by scientific investigation, when serving as 'elements within philosophical arguments' (Popp 2007), endow these arguments with scientific value. Despite all the platitudes about science, lip service to science, use of science generated claims and 
even collaborations with scientists, the method used to justify first order claims about the world is not like the methods scientists use to do the same. And for naturalists to evade the requirement of observation and experiment by holding that 'Science is not identical with experimentation...' and that '... each intellectual discipline has its own rules for justifying its claims...' (Bower, G. H, and Clapper, J. P. 1989, p.245) is both disingenuous and self-defeating.

Note, as already mentioned, none of what has been argued in this paper denies the potentially fruitful partnership of philosophical work with that of the natural or physical sciences. But such a partnership, when there is an actual partnership (and not simply an isolated philosopher foraging for scientific information with which to build an argument), would be one where the philosophical contribution is correctly qualified as something like conceptual, schematic, analytic, conventional, metalinguistic and so on.

But naturalists, we have seen, reject this type of qualification for philosophy. So, what naturalism demands, or at least ought to demand, is that philosophical claims should be subject to the sort of ratification which is enabled through the '... stimulation of his [the scientist-philosopher's] sensory receptors...' (Hacker 2005, p.5), or put differently, ' ... the claims established by philosophers depend on the same kind of empirical support as scientific theories' (Papineau 2014, pp.166-7).

That 'Whatever Next?' is part of a recognisable and organised body of work is undeniable. That it offers a systematic approach to deliberating about mind is also undeniable. That some theories yielded by cognitive science may, or may not, be more consistent with the greater body of its established theories is easy to see. That cognitive science theories which challenge the status quo might find resistance to their introduction into the field seems plausible. Therefore, that their eventual inclusion might lead to revision in other but related areas of cognitive science seems plausible too. That all of the aforementioned also characterises how theories, within one or another natural science, 'behave' is well known. So, yes, if this is what Papineau means, then philosophy is, in principle, like science. But then, so is theology. What naturalists are obliged to do is show evidence of their a posteriori work, if they want to make synthetic claims. When compared to Haynes and Rees, Clark has not provided his reader with an account of the '... stimulation of the sensory receptors...' (Hacker 2005), which is supposed to serve as the corroboration of his primary claim. Haynes and Rees have been at great pains to do exactly this.

There have been no '... skin irritations...' offered in support of Clark's claim that brains are prediction machines. What has been offered is a set of loosely connected broad theoretical positions (e.g. materialism, evolutionary theory, generative and Bayesian models of the brain) and a list of more narrow, but never directly related scientific claims (e.g. the behaviour of the retinal ganglion cells of rabbits and salamanders and binocular rivalry in people). The sensory or empirical observation 
that is required for corroboration of Clark's primary first order claim is, by his own admittance, absent. Yet, despite this significant absence, he is optimistic about his postulation of an imminent grand unified theory of mind.

Justificatory methods are not empirical because one cites scientific findings, or because one's final conclusions are the same as, or consistent with, scientists'. They are not even scientific because they are true. Nor can philosophical claims be likened to claims from within science because a philosopher declares that science is the final arbiter of what there is, or because scientists also use their imaginations (qua Papineau), or because science also has extensive systems of deductive mathematical theory floating free of direct sensory support. Philosophical claims are not synthetic merely because the intention is to not yield trivial, linguistic, conceptual or analytic truths. Nor because the commitment is to factual truth and not linguistic truth. To make this the benchmark for what counts as synthetic is to open the very flood gates which, especially naturalists, should want to keep firmly shut.

The scientism of naturalism is sound insofar as it correctly positions science as the correct arbiter of some questions traditionally addressed in philosophical deliberation. And what the human and other animals' mind are designed for indeed seems like a question for science. But the naturalist claim that philosophers behave like scientists, is wrong, and that they might be able to, whilst working in their quotidian manner, seems implausible.

\section{Conclusion}

I have given reasons for why we should take premises 3 and 4 of my argument to be true. I did so by offering two case studies and compared them with each other. I have, in this sense, given a principled reason, a moral, for why they are not alike. The hope is that the principle elicited from this comparison can be applied to similar cases - of which there are many.

\section{References}

Abrahamsen, A.; Bechtel, W. 2012. History and core themes. In: K. a. R. W. M. Frankish, (ed.) The Cambridge Handbook of Cognitive Science, pp.9-29. Cambridge: Cambridge University Press.

Bower, G. H.; Clapper, J. P. 1989. Experimental Methods in Cognitive Science. In: M. I. Posner (ed.) Foundations of Cognitive Science, pp.245-300. Massachusetts: Massachusetts Institute of Technology.

Churchland, P. 1981. Eliminitave Materialism and the Porpositional Attitudes. The Journal of Philosophy 78(2): 67-90. 
Clark, A. 2013. Whatever next? Preditive brains, situated agents, and the future of cognitive science. Behavioral and brain sciences 36(3): 181-253.

Dennett, D. C. 2003. Freedom Evolves. second ed. New York: Penguin.

Frege, G. 1974. The Foundations of Arithmetic. First ed. Oxford: Basil Blackwell.

Friedman, M. 1997. Philosophical Naturalism. Proceedings and addresses of The American Philosophical Association 71(2): 5-21.

Haack, S. 2009. Six signs of scientism. Available at: http://www.uta.edu/philosophy/faculty/ burgess-jackson/Haack, \%20Six\%20Signs\%20of\%20Scientism.pdf [Accessed 30 November 2016].

Hacker, P. 1996. Wittgenstein's Place in Twentieth Century Analytic Philosophy. Oxford: Blackwell.

- 2005. Passing by the Naturalistic Turn: On Quine's cul-de-sac. Available at: info.sjc. ox.uk/scr/hacker/docs/Quin's\%20cul-de-sac.pdf [Accessed July 2016].

Haug, M. C. (ed.) 2014. Philosophical Methodology: The Armchair Or The Laboratory? London and New York: Routledge.

Haynes, D.; Rees, G. 2006. Decoding mental states from brain activity in humans. Nature Reviews. Neuroscience. July, Volume 7: 523-33.

Lutz, S. 2017. Armchair philosophy naturalized. Synthese.Available at: https://doi.org/10. $1007 / \mathrm{s} 1122$.

Maddy, P. 2000. Naturalism and The A Priori. In: B. P. Peacocke (ed.) New Essays on the A Priori, pp.92-115. Oxford University Press.

- 2007. Second Philosophy. New York: Oxford University Press.

2009. Three forms of Naturalism. Available at: http://www.socsci.uci.edu/ pjmaddy/ bio/3forms.pdf [Accessed 23 July 2016].

Papineau, D. 2014. The poverty of conceptual analysis. In: M. C. Haug (ed.) Philosophical methodology: The armchair or the laboratory?, pp.166-94. New York: Routledge.

Popp, J. A. 2007. Evolution's First Philosophy; John Dewey and the Continuity of Nature. Albany: State University New York Press.

Quine, W. V. O. 1963. Carnap and Logical Truth. In: P. A. Schilpp (ed.) The Philosophy of Rudolph Carnap, pp.385-406. London: Cambridge University Press.

- 1963a. Two dogmas of empiricism. In: From a logical point of view, pp.20-46. New York: Harper Torchbooks.

Rosenberg, A. 2014. Why I am a naturalist. In: M. C. Haug (ed.) Philosophical methodology. The armchair or the laboratory, pp.32-5. New York: Routledge.

Van Fraassen, B. C. 2002. The Empirical Stance. Yale University Press.

Williamson, T. 2014a. What is Naturalism?. In: M. C. Haug (ed.) The Armchair or the Laboratory?, pp.29-31. Routledge.

- 2014b. The unclarity of naturalism. In: M. C. Haug (ed.) Philosophical methodology: The armchair or the laboratory?, p.36. New York: Routledge.

Wolff, J. 2015. Naturalistic quietism or scientific realism?. Available at: link.springer/10.1007/ s11229-015-0873-3 [Accessed July 2016]. 


\section{Notes}

${ }^{1}$ That there are strong arguments, say from conventionalism, for parts of science being $a$ priori and analytic is of no concern to this paper.

${ }^{2}$ It might, to some, seem as if I have in some way scored an own goal by saying this. After all, does Papineau not say that most of philosophy is synthetic and a posteriori and therefore permissible - as it is? No, I have not scored an own goal. What Papineau says and what is the actual case are two different things. This will become clearer as we go on. Summarily: His 'synthetic' and 'a posteriori' for philosophy seems to be completely different to the 'synthetic' and 'a posteriori' which is manifested by scientific investigations.

${ }^{3}$ There is a distinction between ontological and methodological naturalism. Papineau is, as I am, only interested in methodological naturalism. We compare the method of science with the method of philosophy. Which entities philosophers and scientists are, or are not, committed to is of no concern. Justification is the concern.

${ }^{4}$ Henceforth, unless referring to another author, 'a posteriori' will refer to 'observational and experimental'.

${ }^{5}$ Papineau asks his reader to interpret his use of philosophy 'sympathetically' (Papineau 2014, p.167); he assumes that his reader will understand that he speaks about philosophy as construed by current mainstream academic philosophers.

${ }^{6}$ Clark uses 'model' liberally in this paper, but his use might lead to some confusion. From now on: 'model ${ }_{1}$ ' refers to the models which brains, and therefore, minds build of external reality to help with prediction processes. 'Models 2 ' refers to the theoretical models generated by the various sciences and by philosophy about what the brain, and mind, is.

${ }^{7}$ It might, for some, seem that what I should be saying rather about Clark's Whatever Next? is not that it is not like science, but is simply bad science. And that therefore perhaps that it is like science in the same way as bad science would be recognised as science - even though bad. But my claim is that Whatever Next? is qualitatively distinct from science - chiefly due to its deeply argumentative nature. Bad science is, presumably, bad empirical work. Generally speaking it is not bad because it is argumentative in nature, instead of empirical.

${ }^{8}$ This is not Wolff's primary complaint against naturalism in Naturalistic Quietism or Scientific Realism (Wolff 2015), but it is a very pertinent point and one, obviously, of interest to me.

${ }^{9}$ Although, even here I think caution is required; not just any philosophical postulation about the nature of reality will have utility in a scientific environment.

${ }^{10} \mathrm{But}$ are the claims generated by naturalistic philosophy, therefore, a priori and analytic? No. The a priori-a posteriori distinction is not exhaustive, nor is the analytic-synthetic distinction. Ruling out a claim from being a posteriori and synthetic does not, as a matter of course, make it a priori and analytic. Analyticity is a positive feature of a sentence. And so is being justified a priori. People like Kant, Frege, Carnap and many more have given accounts of both analyticity and a priority. For now, just going with our working thesis of these terms, i.e. Frege's, justification is either a priori or a posteriori. However, sometimes there is no proper justification at all. A priori justification happens within logical systems. A posteriori justification happens empirically (observationally, with testing etc). But, sometimes neither have happened. It is not required of, nor possible for, me to discuss these here. All we need to know is that Papineau's claim that scientific claims and philosophical claims are the same 
in terms of being justified a posteriori and, consequently, also in terms of being synthetic, is false.

\section{Acknowledgments}

I would like to thank Dr Rees for his reading of section 3.2 of this paper. Here I discussed his and Dr Haynes' paper on decoding mental states. His corrections to my description and analysis of their paper have been valuable. I also thank the University of KwaZulu-Natal for the postdoctoral research position I held with them over the time of producing this paper. 